OXford Ophthalmological Congress

September 12.

Papers.

Symposium on supra-sellar tumours.

Banquet.

September 13.

Papers.

General Meeting.

Closing Session.

Reception by the Municipality of the Hague.

\title{
OXFORD OPHTHALMOLOGICAL CONGRESS XIXTH ANNUAL MEETING
}

THE XIXth Annual Meeting of the Oxford Ophthalmological Congress was held at Oxford on July 4, 5 and 6 last.

Members met informally at dinner on the 3rd in the Hall of Keble College, which had again offered its hospitality as in former years. The advantages which are gained by the all too short stay in the College, where each member is assigned rooms and becomes for the time being a student again, are quite one of the features of th's successful annual gathering of ophthalmic surgeons, which was founded by the late Robert Doyne nearly twenty years ago. The proceedings of the Congress were held in the Department of Human Anatomy of the University, kindly lent for the purpose by Professor Arthur Thomson, to whom the Congress is under a deep debt of gratitude. In addition to the Scientific Museums, a Commercial Museum was on view in which fourteen well known firms of ophthalmic instrument makers exhibited the latest forms of apparatus and instruments.

The Master this year is Mr. Bernard Cridland, who has been Secretary for the past sixteen years. This appointment has been received with high approval by the members as it is common knowledge amongst them that one of the great factors in the continuous success of the Congress has been the work put into the organisation and arrangements of the meetings by Mr. BERNARD C.RIDLAND. 
An unusually large number of Foreign Members, and others resident abroad, attended the Congress this year, amongst whom were Prof. Josef Meller, of Vienna, Prof. Lundsgaard and Dr. Holgar Ehlers, of Copenhagen, Dr. Holland, C.I.E., of Quetta, Dr. Bernard Samuels, of New York, Dr. Thomas Poole, of Washington, Dr. Swan, of Evanston, Dr. Lichtenberg, of Kansas City, and Dr. J. A. van Heuven, of Utrecht.

The proceedings commenced on the morning of Thursday, July 4, with a short address of welcome by the Master.

Immediately following this Prof. MELLER opened his address with a short historical resumé of the treatment of diseases of the lacrymal sac, pointing out that the idea of making an opening into the nose could be traced back to Celsus. In the eighteenth century, Woolhouse suggested the purely surgical operation of extirpation of the sac, and finally Prof. Meller brought the historical review up to the methods of Toti and West in the present century. Contemporary methods of treatment were then discussed for pure epiphora without ascertainable involvement of the lacrymal passage. From this Prof. Meller passed on to the treatment of pure stenosis and considered those cases which would be benefited by probing. The great value of X-rays being used before treatment was insisted upon, and he deprecated the use of thick probes. Stricturotomy of the duct was then described. The medicamental treatment of chronic dacryocystitis was then fully explained. Following this, the treatment of acute purulent dacryocystitis was illustrated and the operative treatment of chronic dacryocystitis was delineated. The technique of the operation of extirpation of the sac was minutely described and the difficulties emphasised. The various intra-nasal operations were then related and commented upon.

Dr. J. S. Fraser followed, discussing the lacrymal question from the rhinological aspect. He confined his attention to the results of 108 dacryocystotomy operations, describing the technique minutely, its difficulties, complications, and results. The papers were discussed by Mr. HARRISON ButLER and Mr. Edward D. D. DAvis, who mentioned the nasal causes of dacryocystitis, of which in a series of ten cases, lupus caused 5, atrophic rhinitis 1 , enlarged cystic middle turbinate 3 , and carcinoma of the ethmoid 1 , and further stated that his experience of West's operation had not been satisfactory. He emphasised the value of lipiodol in X-ray photographs as a means of diagnosis. Mr. Browning, Mr. Jameson Evans and Prof. Lundsgaard also joined in the discussion, the latter raising the question of tuberculous lacrymal disease, pointing out that it was generally secondary to a nasal infection. He drew attention to the Finsen light, mentioning that it had no perceptible effect on the closed sac but was decidedly favourable when the cavity was open. Prof. Meller replied to the discussion. 
In the afternoon there were demonstrations in the Scientific Museum. Mr. MADDOX showed his cheiroscope and frame-fitting method. Miss MADDox demonstrated a few simple expedients in squint training. Mr. BURDON COOPER showed spectrograms, showing the composition of the ash in the senile cataractous lens. Mr. ThOMSON HENDERSON showed a specimen of an intradural tumour of the optic nerve; Mr. RAYNER BATTEN, a collection of drawings showing disease of the macular region. Mr. ARMSTRONG showed a recording scotometer, and Mr. GEORGE Young a case of transplantation of the whole cornea and conjunctiva.

At the conclusion of the afternoon's proceedings, members and their friends repaired to the gardens of Exeter College for tea, where they were welcomed by the Vice-Principal of Ripon Hall, the Rev. J. S. Bezzant, Fellow of Exeter College, and Mrs. Bezzant, and Mr. Philip Adams, Fellow of Exeter College and Deputy Master of the Congress, and Mrs. Adams, who kindly acted as hosts and hostesses. The Annual Dinner of the Congress was held in the evening in the Hall of Keble College, at which the largest number in the history of the Congress attended. Among the guests were the Dean of the Oxford School of Medicine, Dr. Ainley Walker, the Rev. J. S. and Mrs. Bezzant, Dr. J. S. Fraser and Prof. Meller. In speaking on behalf of the Congress, the Master, Mr. BERNARD CRIDLAND, mentioned that 23 new members had been elected during the year and the total membership was now 411. He regretted to have to record the loss, through death, of Dr. Andrews, of California, and Dr. Beauman, of South Africa. The Master then gave a detailed account of the history of the Congress from the time of its inception, nineteen years ago, pointing out its remarkable and steady progress until it had assumed its present position of importance in the ophthalmological world. After referring to the numerous foreign and over-seas members present, he drew attention to the presence of Mr. Richardson Cross, of Bristol, a member of the original Council of the Congress, and added further that three quarters of the members of the executive of the Congress at the present time were former pupils of $\mathrm{Mr}$. Richardson Cross. The Toast of the Visitors was proposed by the Deputy Master, Mr. Philip Adams, and replied to by Dr. Ainley Walker.

The proceedings on the morning of Friday were opened by Dr. Thомas Poole, of Washington, whose paper on "The effects of disease of the paranasal sinuses upon the fixation point," should be read in the original.

Mr. RIDLEY then read a paper on " An unusual complication of Hodgkin's Disease " in which the lacrymal glands were seriously infected. 
Then followed the Doyne Memorial Lecture, the most important contribution to the proceedings of the Congress.

Instituted in 1916, in memory of the Founder, these lectures have proved the occasion for the appearance of much valuable and original work. This year the lecture was given by Miss IDA MANN, D.Sc., F.R.C.S., the subject being " Some observations on the vascularisation of the vertebrate eye." Prefacing her remarks with a fitting tribute to the founder, the lecturer for the purpose of this study divided the intraocular vessels into three groups, those of the retina, iris, and choroid.

The choroid was only briefly described, emphasis being laid on the vessels of the retina and iris: Reference was made to the stability of the structure of the choroid throughout the phylum, and to certain modifications which appear in some fish, producing the structure known as the choroidal gland. Reference was also made to the reflecting membranes, the argentea in fish, and the tapetum of the carnivora. It was pointed out that the variations of the retinal and iris vessels are of great interest as would be expected because both sets appear relatively late in ontogeny in all species. The development of the hyaloid vessel was minutely described and the varying forms were noted, and it was only in the higher mammals that a single vessel was found.

The main varieties of the adult retinal blood supply which are found among vertebrates are: (1) a completely avascular retina, the blood supply being entirely from the choroid, (2) an avascular retina associated with a pecten, (3) a vascular retina, supplied by vessels lying on its inner surface and (4) a vascular retina supplied by vessels ramifying in its substance.

The modifications of the anterior end of the hyaloid were divided into two groups, those with and without a pupillary membrane during development. The former being confined to the mammals, while the latter embraces the rest of the vertebrates.

The lecture was illustrated by over 60 lantern slides which were of extraordinary interest. 'These were chiefly drawn under slitlamp illumination at the Zoological Gardens, and comprised among them anterior ocular drawings of a salamander, a python and numerous fish.

It is impossible in a short description to convey the extraordinary interest of this lecture, which was delivered in a very clear and lucid manner and commanded the greatest attention. At its conclusion Miss MaNN was presented with the Doyne Memorial Medal for the year.

Mr. Nicholas Hughes then read an original and interesting paper on the structure of the vitreous. This research had been carried out on sheep's eyes in which the vitreous was suspended in a vessel containing a solution of chloride of sodium of a specific 
gravity adjusted to that of the vitreous. Observations were then made with the arc slit-lamp. The investigation showed that the vitreous has a slender attachment to the optic disc and a much firmer union to the ciliary processes. The interior of the vitreous is occupied by membranes which have a remarkable disposition, and their structure was fully described in the paper.

In the afternoon Lt.-Col. H. HerberT read a paper, on "The cement substance of the intraocular muscles and chronic glaucoma," which is impossible to abstract and should be read in the original.

Mr. Hugh Cairns then opened a discussion on "The ocular manifestations found in head injuries." He stated that undue attention had been paid to the actual fracture of the skull and too little to the underlying brain. Emphasis was laid on the increase of intracranial pressure caused by haemorrhage or oedema of the brain substance.

It was difficult to decide which cases would benefit by operation and which would not. Blurring of the optic discs is seen in many cases where there is a large. blood clot in the brain ; in 80 patients, only 7 showed definite papilloedema; this latter sign was an indication for operative measures which would give the patient a better chance and avoid the chronic ill health which so frequently follows head injuries. Dilatation and fixation of the pupil indicated the side of the more serious lesion. Homonymous visual field defects were rarely seen in civil practice, and injury to the fibre tracts and nuclei were also rare. Persistent headache and photopsia following a head injury was not functional but was probably due to an unresolved cerebral contusion.

Mr. Charles Goulden then discussed the subject from the point of view. of the ophthalmic surgeon. He described very fully the direction which fractures take when blows are applied to certain parts of the skull, and showed that a fracture involving the optic canal can occur in any fracture of the skull but is most common when the blow is in the neighbourhood of the external angular process. The various ocular symptoms due to haemorrhage into the sheath of the optic nerve were described and the important pupillary reactions well portrayed. The various ocular paralyses were minutely gone into and their localising value explained. Pulsating exophthalmos and its causation were also described, as were haemorrhages into the orbital region, dislocation of the eyeball and its mechanism.

On Saturday morning Mr. Bernard Samuels, of New York, gave a paper entitled "Necrosis of the iris," the results of his research work in the Vienna Clinic under Prof. Fuchs. It was illustrated by a number of slides which demonstrated the condition very clearly. It was discussed by Prof. MrLler, who emphasised 
the difference between primary and secondary necrosis of the iris.

Dr. George Young, of Colchester, was to have given the next paper but was unfortunately taken ill. Mr. Philip Adams, the Deputy Master, kindly filled the hiatus by reading an interesting paper on three cases of toxic amblyopia, due respectively to iodoform, digitalin, and chlorodyne.

Dr. H. T. Holland, C.I.E., of Quetta, then read a very instructive paper on "Iritis as a post-operative complication of cataract extraction," being a review of 2,627 consecutive extractions for cataract, of which the large majority had been intracapsular, and showed that a higher proportion of iritis took place in those operations which were performed with capsulotomy.

This concluded the proceedings; the attendance of 112 constituted a record in the history of the Congress.

C. Russ Wood.

\section{MEETING OF THE BRITISH MEDICAL ASSOCIATION, MANCHESTER, JULY 24 and 25, 1929}

\section{Section of Ophthalmology}

After a short introductory address by Mr. Gray ClegG, the President of the Section, Mr. MacCallan introduced a discussion on "Toxic absorption due to focal septic lesions and its effect on the production of eye diseases." He detailed the various sites of the septic foci, the more common being dental apical abscesses and septic infections of the tonsils, especially in children. Less commonly, intestinal sepsis, chronic appendicitis and sepsis of the pelvic organs in women. The various ocular diseases which were attributed to these causes were corneal ulcer, episcleritis, conjunctivitis, chalazion, iridocyclitis, phlyctenular conjunctivitis, dacryocystitis, retinal hyperaemia, vitreous opacities, primary glaucoma, cataract and progressive myopia.

Dr. ARTHUR HURST said that the mouth should be considered as a whole and in the examination of the teeth all those that were dead should be regarded as possible sources of infection and, even in edentulous patients, buried septic roots should be searched for and extracted if found. He agreed that the tonsils and paranasal sinuses were a frequent source of infection, but did not think that duodenal ulceration was to be regarded as a cause. In Dr. Hurst's experience achlorhydria was a common cause of septic infection due to the loss of bactericidal power of the gastric juice. $\mathrm{Mr}$. 